\title{
Influência de métodos de secagem na conservação de sementes de Ipê-branco ${ }^{1}$
}

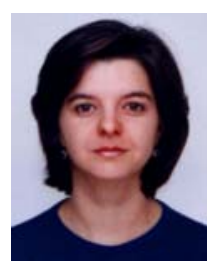

Patrícia Degan², Ivor B. de Aguiar ${ }^{3}$, Rubens Sader ${ }^{3}$, Dilermando Perecin ${ }^{3}$ \& Luciana R. Pinto ${ }^{3}$

1 Parte do Trabalho de Graduação apresentado pelo primeiro autor à FCAV/UNESP

2 Rua Amorim 147, CEP 13480-628, Limeira, SP. Fone: (19) 3451-2907. E-mail: terrabrasil@terra.com.br (Foto)

${ }^{3}$ FCAV/UNESP, Departamento de Produção Vegetal, Via de Acesso Prof. Paulo Donato Castellane, CEP 14884-900, Jaboticabal, SP. E-mail: ivor@netsite.com.br, rsader@fcav.unesp.br, perecin@fcav.unesp.br, Irpinto@ciagri.carpa.usp.br

Protocolo $073-28 / 5 / 2001$

\begin{abstract}
Resumo: Sementes de Tabebuia roseo-alba (ipê-branco) com 21,9\% de água e 56,5\% de germinação, foram submetidas à secagem em liofilizador, câmara seca e estufa. Depois da secagem, o teor de água das sementes foi reduzido para 3,7, 4,0 e 11,7\% e a germinação para $49,0,44,7$ e 45,5\%, respectivamente. As sementes liofilizadas foram acondicionadas em embalagem impermeável e as não liofilizadas em embalagens permeável e impermeável. Após o acondicionamento, as sementes foram armazenadas nos ambientes normal de laboratório, de câmara seca e de câmara fria. Avaliações da porcentagem de germinação (capacidade germinativa) das sementes foram feitas periodicamente, durante $300 \mathrm{~d}$ de armazenamento. As sementes revelaram, durante o armazenamento, comportamento idêntico ao das classificadas como ortodoxas. Quando armazenadas em ambiente normal de laboratório, as sementes se deterioraram rapidamente. As sementes liofilizadas conservaram sua capacidade germinativa quando armazenadas em câmara fria. As sementes secadas em câmara seca, acondicionadas nas embalagens permeável e impermeável, e as secadas em estufa, acondicionadas em embalagem permeável, conservaram sua capacidade germinativa quando armazenadas na câmara seca e na câmara fria.
\end{abstract}

Palavras-chave: Tabebuia roseo-alba, semente florestal, acondicionamento, embalagem, armazenamento

\section{The influence of drying methods on the conservation of Tabebuia roseo-alba (Ridl.) Sand. seeds}

\begin{abstract}
Tabebuia roseo-alba (Bignoniaceae) is a late secondary tree species native to Brazil, important for ornamental, medicinal and wood purposes. Seeds of this species with $21.9 \%$ moisture content and $56.5 \%$ germination were submitted to drying in lyophilizer, dry chamber and forced air oven. After drying, seed moisture content was reduced to $3.7,4.0$ and $11.7 \%$, and germination percentage to $49.0,44.7$ and $45.5 \%$, respectively. Lyophilized seeds were packed in impermeable containers and non-lyophilized seeds were packed in both permeable and impermeable containers. After packaging, seeds were stored under room, dry chamber and cold chamber conditions. Seed germination percentage (germinative capacity) was periodically evaluated up to 300 days of storage. During storage, the seeds had a behavior of those classified as orthodox. Seeds stored at laboratory room temperature deteriorated rapidly. The lyophilized seeds conserved their germinative capacity when stored in cold chambers. Seeds dried in dry chambers packed in permeable and impermeable containers and those dried in ovens packed in permeable containers maintained the germinative capacity when stored in dry and cold chambers.
\end{abstract}

Key words: forestry seed, packaging, container, storage, germination

\section{INTRODUÇÃO}

Muitas das espécies do gênero Tabebuia (Bignoniaceae) são nativas do Brasil e vulgarmente denominadas ipê; são espécies arbóreas de grande valor ornamental, medicinal e madeireiro (Lorenzi, 1992; Carvalho, 1994). Pertencem ao grupo ecológico das secundárias tardias (Ferretti et al., 1995) e o nome vulgar de cada espécie é complementado pela coloração das flores, que pode ser branca, amarela, rosa ou roxa. Dentre as espécies nativas do Brasil mais cultivadas, T. roseo-alba (Ridl.) Sand. é a única que produz flores brancas (Maeda \& Matthes, 1984). 
Pela importância das diferentes espécies e da curta longevidade natural de suas sementes, pesquisas envolvendo o armazenamento das sementes de ipê vêm sendo conduzidas e publicadas desde a década de 70 (Carvalho et al., 1976; Kano et al., 1978; Freitas et al., 1979; Kageyama \& Marquez, 1981; Natale \& Carvalho, 1983; Maeda \& Matthes, 1984; Pinto et al., 1986; Figliolia et al., 1986/1988; Figliolia, 1988; Cunha et al., 1992; Kageyama et al., 1992; Mello \& Eira, 1995). Os resultados dessas pesquisas revelaram o comportamento ortodoxo das sementes, caracterizado por Roberts (1973) pela eficiente conservação com baixo teor de água, armazenadas em ambiente com baixos níveis de temperatura e umidade relativa do ar.

A curta longevidade natural das sementes de ipê está ligada à pequena quantidade de substâncias de reserva armazenadas na semente (Kageyama \& Marquez, 1981) e ao elevado teor de óleo em sua composição química. Freitas et al. (1979) constataram $28,7 \%$ de óleo em sementes de T. serratifolia (ipêamarelo) e Degan et al. (1997) detectaram 18,6\% de óleo em sementes de T. roseo-alba (ipê-branco). De acordo com Harrington (1972), sementes ricas em óleo perdem a viabilidade com maior facilidade que as ricas em proteínas e carboidratos, devido à maior instabilidade daquele componente.

Para reduzir o teor de água das sementes a níveis adequados ao seu armazenamento, geralmente tem sido efetuada a secagem em estufa, com temperatura variando de 40 a $45^{\circ} \mathrm{C}$ (Carneiro \& Aguiar, 1993; Aguiar, 1995). Entretanto, Miyasaki \& Cândido (1978) e Pinto et al. (1986) verificaram que as sementes de ipê são sensíveis à secagem em estufa, principalmente quando o período de secagem é prolongado, resultando em rápida perda da capacidade germinativa e do vigor.

O processo de liofilização vem sendo testado para a secagem de sementes de várias espécies arbóreas, para fins de armazenamento. Resultados positivos foram constatados por Natale \& Carvalho (1983) para sementes de Tabebuia sp (ipêroxo) e por Figliolia et al. (1986/1988) para sementes de T. vellosoi (ipê-amarelo). $\mathrm{O}$ aspecto favorável desse processo é que as sementes são desidratadas a baixo teor de água, sem alteração em sua composição química, e podem ser armazenadas em ambiente normal de laboratório, por considerável período de tempo, sem deterioração.

Em vista do exposto, o presente trabalho foi desenvolvido com o objetivo de se estudar o efeito de diferentes métodos de secagem na conservação de sementes de T. roseo-alba (ipêbranco) armazenadas em diferentes ambientes.

\section{MATERIAL E MÉTODOS}

As sementes de ipê-branco utilizadas neste trabalho foram extraídas de frutos colhidos no município de Jaboticabal, SP, de 25 árvores cujo florescimento ocorreu em agosto de 1992. A colheita foi efetuada em outubro do mesmo ano, quando os frutos iniciaram a abertura espontânea, ainda nas árvores. Depois da colheita, os frutos foram expostos ao sol por oito horas, a fim de complementar a sua abertura e a liberação das sementes.

As sementes liberadas foram homogeneizadas e a seguir foram retiradas amostras para a determinação do teor de água e da porcentagem de germinação. $O$ teor de água foi determinado pelo método de estufa a $105^{\circ} \mathrm{C}$, descrito nas Regras para Análise de Sementes (Brasil, 1992), com duas repetições de 100 sementes.
O teste de germinação foi conduzido a $25^{\circ} \mathrm{C}$, sob fotoperíodo de $8 \mathrm{~h}$. Foram adotadas quatro repetições de 25 sementes, colocadas sobre papel de filtro previamente umedecido com água destilada, em caixas plásticas transparentes de 11 x $11 \mathrm{~cm}$, com tampa. Antes da instalação do teste, as caixas foram desinfestadas com hipoclorito de sódio a $5 \%$ e as sementes tratadas com o mesmo produto, a $2 \%$, durante $2 \mathrm{~min}$. A contagem de sementes germinadas, que produziram plântulas normais, foi efetuada aos 7, 14 e $21 \mathrm{~d}$, determinando-se a porcentagem final de germinação.

O lote de sementes foi dividido em três sublotes, cada um submetido a um método de secagem: no liofilizador, em câmara seca e em estufa. No liofilizador, as sementes foram inicialmente congeladas a $-40^{\circ} \mathrm{C}$ e depois submetidas a vácuo, sob pressão de $13,3 \mathrm{~Pa}$, durante $16 \mathrm{~h}$. Na câmara seca, com $40 \%$ de umidade relativa do ar e temperatura de $34^{\circ} \mathrm{C}$ (bulbo seco) e $23^{\circ} \mathrm{C}$ (bulbo úmido), as sementes permaneceram pelo período de $24 \mathrm{~h}$. Na estufa com circulação forçada de ar, as sementes permaneceram por 30 min a $35^{\circ} \mathrm{C}$. Para a secagem na câmara seca e na estufa, as sementes foram espalhadas em camada fina e homogênea, em bandeja de metal.

Depois da secagem, foram novamente determinados o teor de água e a porcentagem de germinação das sementes, conforme o procedimento descrito anteriormente; em seguida, as sementes liofilizadas foram acondicionadas em saco plástico envolto por uma folha de alumínio e colocado dentro de outro saco plástico, que foi fechado termicamente; esta embalagem foi considerada impermeável. As sementes submetidas à secagem na câmara seca e na estufa foram acondicionadas em embalagens permeável e impermeável, sendo esta a mesma adotada para as sementes liofilizadas e, como embalagem permeável, foi utilizado saco de papel.

As sementes liofilizadas foram acondicionadas apenas em embalagem impermeável, porque o material liofilizado se deteriora quando iluminado (Natale \& Carvalho, 1983). Para evitar a iluminação, os sacos plásticos contendo as sementes foram envoltos por papel alumínio, tornando a embalagem impermeável à água (Zanon \& Ramos, 1986).

As sementes assim acondicionadas foram armazenadas em três ambientes: normal de laboratório (sem controle da temperatura e da umidade relativa do ar), câmara seca (sem controle da temperatura e com umidade relativa do ar em torno de $40 \%)$ e de câmara fria $\left(10^{\circ} \mathrm{Ce} 86 \%\right.$ de umidade relativa do ar). $\mathrm{O}$ período de armazenamento foi de $300 \mathrm{~d}$, tendo sido feita avaliação da porcentagem de germinação das sementes a cada $30 \mathrm{~d}$, até $120 \mathrm{~d}$ e, posteriormente, a cada $60 \mathrm{~d}$. Para cada tratamento foram utilizadas sete embalagens, sendo cada uma aberta na data de cada avaliação. O procedimento adotado para determinar a porcentagem de germinação (germinabilidade ou capacidade germinativa) foi o mesmo descrito anteriormente.

Adotou-se o delineamento experimental inteiramente casualizado e as análises estatísticas foram efetuadas com as médias das quatro repetições de cada tratamento. As análises de variância foram efetuadas sob o esquema fatorial desbalanceado, considerando-se que as sementes liofilizadas não foram acondicionadas em embalagem permeável. Os fatores testados foram (a) método de secagem, (b) permeabilidade da embalagem, (c) ambiente de armazenamento e (d) período de armazenamento. A comparação entre as médias foi feita com a aplicação do teste t, a $5 \%$ de probabilidade. 
Foi calculada a diferença mínima significativa com base nos tratamentos cujos dados foram mais homogêneos, a fim de permitir melhor estimativa para o resíduo. Esta diferença mínima foi utilizada para se comparar a germinação obtida depois de cada período de armazenamento com o valor inicial, em cada tratamento. Consideraram-se menos homogêneos os tratamentos cuja germinação foi rapidamente reduzida, evidenciando variabilidade e interação muito acentuadas ao longo do período de armazenamento.

\section{RESULTADOS E DISCUSSÃO}

Antes da secagem, as sementes de ipê-branco se apresentaram com $21,9 \%$ de água e $56,5 \%$ de germinação. O teor de água e a porcentagem de germinação das sementes foram reduzidos, respectivamente, para 3,7 e $49,0 \%$ após secagem no liofilizador, 4,0 e 44,7\% após secagem na câmara seca e 11,7 e $45,5 \%$ após secagem em estufa.

A análise de variância referente aos dados obtidos durante o período de armazenamento revelou significância para os quatro fatores testados, bem como para as interações entre eles. Para isolar essas interações fez-se, numa segunda etapa, uma análise para cada método de secagem.

$O$ valor do coeficiente de variação, obtido para os tratamentos mais homogêneos (sementes liofilizadas e armazenadas em câmara seca e câmara fria; sementes secadas em câmara seca e armazenadas em câmara seca e câmara fria; sementes secadas em estufa, acondicionadas em embalagem permeável e armazenadas em câmara seca e câmara fria), foi de $8,77 \%$. Para esses tratamentos, a diferença mínima significativa foi de 12,03. Esse valor foi utilizado para se comparar as médias de cada período de armazenamento com a germinação inicial, em todos os tratamentos.

Apesar do baixo teor de água $(3,7 \%)$ as sementes liofilizadas sofreram significativa redução da germinabilidade depois de $60 \mathrm{~d}$ de armazenamento em ambiente normal de laboratório e depois de $120 \mathrm{~d}$ de armazenamento em câmara seca (Tabela 1). A variação da temperatura, nesses ambientes, foi responsável pela redução na porcentagem de germinação das sementes durante o armazenamento. Em câmara fria, contudo, a capacidade germinativa das sementes, depois de $300 \mathrm{~d}$ de armazenamento, não diferiu significativamente do valor inicial, indicando que a baixa temperatura diminuiu a atividade respiratória das sementes, contribuindo para a sua conservação.

Tabela 1. Porcentagem de germinação $0^{(*)}$ de sementes liofilizadas de Tabebuia roseo-alba acondicionadas em embalagem impermeável e armazenadas em diferentes ambientes durante diferentes períodos

\begin{tabular}{cccc}
\hline \multirow{2}{*}{$\begin{array}{c}\text { Período de } \\
\text { Armazenamento }\end{array}$ (dia) } & \multicolumn{3}{c}{ Ambiente de Armazenamento } \\
\cline { 2 - 4 } & Laboratório & Câmara Seca & Câmara Fria \\
\hline 0 & $49,0 \mathrm{a}$ & $49,0 \mathrm{a}$ & $49,0 \mathrm{a}$ \\
30 & $42,8 \mathrm{a}$ & $37,5 \mathrm{a}$ & $39,1 \mathrm{a}$ \\
60 & $11,5 \mathrm{~b}$ & $40,3 \mathrm{a}$ & $42,6 \mathrm{a}$ \\
90 & $8,2 \mathrm{~b}$ & $47,9 \mathrm{a}$ & $45,0 \mathrm{a}$ \\
120 & $0,0 \mathrm{~b}$ & $36,1 \mathrm{~b}$ & $44,5 \mathrm{a}$ \\
180 & $0,0 \mathrm{~b}$ & $25,7 \mathrm{~b}$ & $39,1 \mathrm{a}$ \\
240 & $0,0 \mathrm{~b}$ & $15,8 \mathrm{~b}$ & $37,2 \mathrm{a}$ \\
300 & $0,0 \mathrm{~b}$ & $2,9 \mathrm{~b}$ & $39,2 \mathrm{a}$ \\
\hline
\end{tabular}

Outros trabalhos desenvolvidos com sementes de ipê revelaram a eficiência da liofilização na conservação das sementes armazenadas em ambiente normal de laboratório. Para ipê-roxo (Tabebuia sp) a capacidade germinativa das sementes foi mantida durante $360 \mathrm{~d}$, quando liofilizadas, e durante apenas 60 d quando não liofilizadas (Natale \& Carvalho, 1983). Da mesma forma, sementes liofilizadas de Tabebuia vellosoi (ipêamarelo) mantiveram a capacidade germinativa durante $240 \mathrm{~d}$, enquanto as sementes não liofilizadas apresentaram significativa redução na germinabilidade, já com $60 \mathrm{~d}$ de armazenamento (Figliolia et al., 1986/1988). As condições de pressão e temperatura adotadas na ocasião da liofilização foram diferentes, em cada trabalho, sugerindo que as condições adotadas na presente pesquisa podem ter causado injúrias às sementes, prejudicando o seu potencial de armazenamento nos ambientes em que houve variação da temperatura.

Esta suposição ficou fortalecida pela eficiente conservação das sementes de ipê-branco secadas em câmara seca, até um teor de água semelhante ao obtido com a liofilização $(4,0 \%)$, acondicionadas em embalagem impermeável e armazenadas em câmara seca (Tabela 2). Nesse ambiente houve variação da temperatura e as sementes mantiveram sua germinabilidade durante todo o período de armazenamento estudado (300 d).

Tabela 2. Porcentagem de germinação ${ }^{(*)}$ de sementes de Tabebuia roseo-alba secadas em câmara seca e estufa, acondicionadas em diferentes embalagens e armazenadas em diferentes ambientes durante diferentes períodos

\begin{tabular}{|c|c|c|c|c|c|c|}
\hline \multirow{2}{*}{$\begin{array}{l}\text { P. Armaz. } \\
\text { (d) }\end{array}$} & \multicolumn{3}{|c|}{ Embalagem Permeável } & \multicolumn{3}{|c|}{ Embalagem Impermeável } \\
\hline & Lab. & C.S. & C.F. & Lab. & C.S. & C.F. \\
\hline \multicolumn{7}{|c|}{ A. Secagem em Câmara Seca } \\
\hline 0 & $44,7 \mathrm{a}$ & $44,7 \mathrm{a}$ & $44,7 \mathrm{a}$ & $44,7 \mathrm{a}$ & $44,7 \mathrm{a}$ & $44,7 \mathrm{a}$ \\
\hline 30 & $49,1 \mathrm{a}$ & $51,4 \mathrm{a}$ & $47,3 \mathrm{a}$ & $43,8 \mathrm{a}$ & $43,2 \mathrm{a}$ & $50,9 \mathrm{a}$ \\
\hline 60 & $39,2 \mathrm{a}$ & $49,6 \mathrm{a}$ & $56,0 \mathrm{a}$ & $39,1 \mathrm{a}$ & $49,7 \mathrm{a}$ & $49,6 \mathrm{a}$ \\
\hline 90 & $31,6 \mathrm{~b}$ & $55,1 \mathrm{a}$ & $53,8 \mathrm{a}$ & $38,0 \mathrm{a}$ & $51,5 \mathrm{a}$ & $53,1 \mathrm{a}$ \\
\hline 120 & $2,9 \mathrm{~b}$ & $49,2 \mathrm{a}$ & $55,9 \mathrm{a}$ & $19,3 \mathrm{~b}$ & $49,1 \mathrm{a}$ & $47,7 \mathrm{a}$ \\
\hline 180 & $0,0 \mathrm{~b}$ & $44,4 \mathrm{a}$ & $46,8 \mathrm{a}$ & $0,0 \mathrm{~b}$ & $43,5 \mathrm{a}$ & $47,9 \mathrm{a}$ \\
\hline 240 & $0,0 \mathrm{~b}$ & $46,8 \mathrm{a}$ & $52,6 \mathrm{a}$ & $0,0 \mathrm{~b}$ & $42,7 \mathrm{a}$ & $52,0 \mathrm{a}$ \\
\hline 300 & $0,0 \mathrm{~b}$ & $39,2 \mathrm{a}$ & $46,8 \mathrm{a}$ & $0,0 \mathrm{~b}$ & $40,3 \mathrm{a}$ & $53,8 \mathrm{a}$ \\
\hline \multicolumn{7}{|c|}{ B. Secagem em Estufa } \\
\hline 0 & $45,5 \mathrm{a}$ & $45,5 \mathrm{a}$ & $45,5 \mathrm{a}$ & $45,5 \mathrm{a}$ & $45,5 \mathrm{a}$ & $45,5 \mathrm{a}$ \\
\hline 30 & $45,6 \mathrm{a}$ & $50,9 \mathrm{a}$ & $47,5 \mathrm{a}$ & $0,0 \mathrm{~b}$ & $0,0 \mathrm{~b}$ & $50,3 \mathrm{a}$ \\
\hline 60 & $38,6 \mathrm{a}$ & $50,9 \mathrm{a}$ & $52,5 \mathrm{a}$ & $0,0 \mathrm{~b}$ & $1,4 \mathrm{~b}$ & $42,1 \mathrm{a}$ \\
\hline 90 & $9,9 \mathrm{~b}$ & $55,3 \mathrm{a}$ & $55,6 \mathrm{a}$ & $12,9 \mathrm{~b}$ & $2,9 \mathrm{~b}$ & $44,4 \mathrm{a}$ \\
\hline 120 & $0,0 \mathrm{~b}$ & $54,8 \mathrm{a}$ & $56,7 \mathrm{a}$ & $0,0 \mathrm{~b}$ & $0,0 \mathrm{~b}$ & $10,8 \mathrm{~b}$ \\
\hline 180 & $0,0 \mathrm{~b}$ & $47,3 \mathrm{a}$ & $52,8 \mathrm{a}$ & $0,0 \mathrm{~b}$ & $0,0 \mathrm{~b}$ & $0,0 \mathrm{~b}$ \\
\hline 240 & $0,0 \mathrm{~b}$ & $47,3 \mathrm{a}$ & $52,0 \mathrm{a}$ & $0,0 \mathrm{~b}$ & $0,0 \mathrm{~b}$ & $0,0 \mathrm{~b}$ \\
\hline 300 & $0,0 \mathrm{~b}$ & $45,6 \mathrm{a}$ & $48,0 \mathrm{a}$ & $0,0 \mathrm{~b}$ & $0,0 \mathrm{~b}$ & $0,0 \mathrm{~b}$ \\
\hline
\end{tabular}

${ }^{(*)}$ Letras minúsculas em cada coluna, comparam médias de cada período de armazenamento com o valor inicial $(0 \mathrm{~d})$, pelo teste $\mathrm{t}$, a $5 \%$ de probabilidade

P. Armaz. - Período de Armazenamento; Lab. - Laboratório; C.S. - Câmara Seca; C.F. - Câmara Fria

Quando a secagem ocorreu em câmara seca, bons resultados foram obtidos também com o armazenamento, em câmara fria, das sementes acondicionadas nas embalagens permeável e impermeável (Tabela 2A). As sementes acondicionadas em embalagem permeável também foram conservadas eficientemente na câmara seca. Em ambiente normal de laboratório, entretanto, a capacidade germinativa das sementes foi mantida durante apenas $60 \mathrm{~d}$, quando acondicionadas em embalagem permeável, e durante $90 \mathrm{~d}$ quando acondicionadas em embalagem impermeável. 
Quando as sementes de ipê-branco foram acondicionadas com maior teor de água (11,7\%), depois da secagem em estufa, o ambiente normal de laboratório não foi eficiente para conservar a sua germinabilidade, tanto em embalagem permeável como impermeável (Tabela 2B). O armazenamento em câmara seca foi eficiente para conservar as sementes acondicionadas em embalagem permeável, que permitiu a passagem de vapor d'água para o ambiente com baixa umidade relativa do ar (câmara seca) até atingir o ponto de equilíbrio higroscópico (Zanon \& Ramos, 1986). Por outro lado, a embalagem impermeável não permitiu essa troca de umidade, conduzindo à rápida deterioração das sementes. $\mathrm{O}$ armazenamento em câmara fria foi eficiente apenas para as sementes acondicionadas em embalagem permeável, revelando que o teor de água das sementes foi muito elevado para o acondicionamento em embalagem impermeável. Para o acondicionamento nesse tipo de embalagem, é recomendável que o teor de água das sementes seja de 4 a 9\% (Zanon \& Ramos, 1986; Carneiro \& Aguiar, 1993; Aguiar, 1995).

Os resultados obtidos neste trabalho comprovaram o comportamento ortodoxo das sementes de ipê-branco, que mantiveram sua qualidade fisiológica quando armazenadas com baixo teor de água e suportaram baixa temperatura durante o armazenamento (Zanon \& Ramos, 1986; Carneiro \& Aguiar, 1993; Aguiar, 1995). Este comportamento já havia sido observado, para a mesma espécie, por Mello \& Eira (1995). Os autores verificaram que sementes de ipê-branco com $9 \%$ de umidade, acondicionadas em embalagem impermeável, mantiveram o seu poder germinativo durante dois anos, armazenadas a $-20^{\circ} \mathrm{C}$.

Embora neste trabalho as sementes de ipê-branco tenham sido colhidas no estádio maduro, a germinação máxima obtida foi de 56,7\%. Mello \& Eira (1995) também obtiveram germinação máxima variando de 50 a $60 \%$, para a mesma espécie. Esses resultados estão de acordo com a informação relatada por Lorenzi (1992) de que as sementes de ipê-branco germinam em baixa porcentagem, mas geralmente superior a $40 \%$.

\section{CONCLUSÕES}

1. A liofilização não foi eficiente para conservar as sementes de ipê-branco nos ambientes normal de laboratório e de câmara seca.

2. O ambiente normal de laboratório não foi eficiente para conservar as sementes secadas em câmara seca e em estufa, acondicionadas nas embalagens permeável e impermeável.

3. O ambiente da câmara seca foi eficiente para conservar as sementes secadas em câmara seca, acondicionadas nas embalagens permeável e impermeável, e as sementes secadas em estufa, acondicionadas em embalagem permeável.

4. O ambiente de câmara fria foi eficiente para conservar as sementes secadas em câmara seca e em estufa, acondicionadas em embalagem permeável, e as sementes liofilizadas e secadas em câmara seca, acondicionadas em embalagem impermeável.

5. As sementes de ipê-branco revelaram, durante o armazenamento, comportamento das classificadas como ortodoxas.

\section{LITERATURA CITADA}

Aguiar, I.B. Conservação de sementes. In: Silva, A.; PiñaRodrigues, F.C.M; Figliolia, M.B. Manual técnico de sementes florestais. São Paulo: Instituto Florestal, 1995. p.33-44. Série Registros, 14

Brasil. Ministério da Agricultura e Reforma Agrária. Regras para análise de sementes. Brasília: SNDA/DNDV/CLAV, 1992. 365p.

Carneiro, J.G.A.; Aguiar, I.B. Armazenamento de sementes. In: Aguiar, I.B.; Piña-Rodrigues, F.C.M.; Figliolia, M.B. Sementes florestais tropicais. Brasília: ABRATES, 1993. p.333-350.

Carvalho, N.M.; Góes, M.; Aguiar, I.B.; Fernandes, P.D. Armazenamento de sementes de ipê-amarelo (Tabebuia chrysotricha). Científica, Jaboticabal, v.4, n.3, p.315-319, 1976.

Carvalho, P.E.R. Espécies florestais brasileiras: recomendações silviculturais, potencialidades e uso da madeira. Colombo: CNPF/EMBRAPA, 1994.369p.

Cunha, R.; Salomão, A.N.; Eira, M.T.S.; Mello, C.M.C.; Tanaka, D.M. Métodos para conservação a longo prazo de sementes de Tabebuia spp - Bignoniaceae. Revista do Instituto Florestal, São Paulo, v.4, p.675-678, 1992.

Degan, P.; Aguiar, I.B.; Sader, R.; Pinto, L.R. Composição química, sanidade, secagem e germinação de sementes de ipê-branco (Tabebuia roseo-alba (Ridl.) Sand. Bignoniaceae). Revista Brasileira de Horticultura Ornamental, Campinas, v.3, n.1, p.41-47, 1997.

Ferretti, A.R.; Kageyama, P.Y.; Árbocz, G.F.; Santos, J.D.; Barros, M.I.A.; Lorzat, R.F.; Oliveira, C. Classificação das espécies arbóreas em grupos ecológicos para revegetação com nativas no Estado de São Paulo. Florestar Estatístico, São Paulo, v.3, n.7, p.73-77, 1995.

Figliolia, M.B. Conservação de sementes de essências florestais. Boletim Técnico do Instituto Florestal, São Paulo, n.42, p.1 $18,1988$.

Figliolia, M.B.; Silva, A.; Jardim, D.C.P.; Iwane, M.S.S. Viabilidade de sementes liofilizadas de essências florestais nativas. Silvicultura em São Paulo, São Paulo, v.20/22, p.47$55,1986 / 88$.

Freitas, S.C.; Cândido, J.F.; Condé, A.R.; Hara, T. Determinação de equilíbrio higroscópico e viabilidade de sementes de ipêamarelo (Tabebuia serratifolia (Vahl) Nichols) armazenadas em diferentes umidades relativas. Revista Árvore, Viçosa, v.3, n.2, p.135-144, 1979.

Harrington, J.F. Seed storage and longevity. In: Kozlowski, T.T. Seed biology. New York: Academic Press, 1972. v.3, p.145245.

Kageyama, P.Y.; Marquez, F.C.M. Comportamento de sementes de curta longevidade armazenadas com diferentes teores de umidade inicial: gênero Tabebuia. In: Reunion sobre Problemas en Semillas Forestales Tropicales, 1980, San Felipe-Bacalar. Memoria... México: INIF, 1981.v.1, p.347-352. Publicación Especial, 35

Kageyama, P.Y.; Sanchez, S.P.A.; Ferraz, E.M.; Souza, L.M.C. Armazenamento de sementes de três espécies nativas (Tabebuia heptaphylla, Erytrhina verna e Chorisia speciosa). Revista do Instituto Florestal, São Paulo, v.4, p.435-439, 1992. 
Kano, N.K.; Márquez, F.C.M.; Kageyama, P.Y. Armazenamento de sementes de ipê-dourado (Tabebuia sp). Instituto de Pesquisa e Estudos Florestais, Piracicaba, n.17, p.13-23, 1978.

Lorenzi, H. Árvores brasileiras: manual de identificação e cultivo de plantas arbóreas nativas do Brasil. Nova Odessa: Editora Plantarum, 1992. 252p.

Maeda, J.A.; Matthes, L.A.F. Conservação de sementes de ipê. Bragantia, Campinas, v.43, n.1, p.51-61, 1984.

Mello, C.M.C.; Eira, M.T.S. Conservação de sementes de ipês (Tabebuia spp.). Revista Árvore, Viçosa, v.19, n.4, p.427-432, 1995.

Miyasaki, J.M.; Cândido, J.F. Secagem de sementes de ipê amarelo (Tabebuia serratifolia Vall/Don). Seiva, Viçosa, n.85, p.12-17, 1978.
Natale, W.; Carvalho, N.M. A liofilização como método de secagem de sementes de ipê-roxo (Tabebuia sp). Revista Brasileira de Armazenamento, Viçosa, v.8, n.1/2, p.35-37, 1983.

Pinto, M.M.; Sader, R.; Barbosa, J.M. Influência do tempo de secagem e do armazenamento sobre a viabilidade das sementes de ipê-rosa. Revista Brasileira de Sementes, Brasília, v.8, n.1, p.37-47, 1986.

Roberts, E.H. Predicting the storage life of seeds. Seed Science and Technology, Zürich, v.1, n.3, p.499-514, 1973.

Zanon, A.; Ramos, A. Armazenamento de sementes de espécies florestais. In: Simpósio Brasileiro sobre Tecnologia de Sementes Florestais, 1, 1984, Belo Horizonte. Anais... Brasília: ABRATES, 1986. p.285-316. 